\title{
Roy Hill waste landform design and construction process
}

\author{
V de San Miguel Roy Hill Iron Ore Pty Ltd, Australia \\ T Stone Roy Hill Iron Ore Pty Ltd, Australia
}

M Braimbridge Mine Earth Pty Ltd, Australia

S Mackenzie Mine Earth Pty Ltd, Australia

\begin{abstract}
The Roy Hill iron ore mine is located approximately $115 \mathrm{~km}$ north of Newman in the Pilbara region of Western Australia and produces 55 million tonnes of iron ore per annum.

Waste rock landform (WRL) construction and progressive rehabilitation is in the early stages at Roy Hill. Given the scale of the operation however, implementing a practical and effective compliance to design process is critical in achieving high quality rehabilitation outcomes.

Conceptual closure designs are developed with the intent of achieving high quality outcomes, but achieving the intended outcome is dependent on multiple factors. These include: ongoing changes to the mine plan; conformance to construction specifications and tolerances; machine accuracy, operator skill and effective supervision; survey controls; the nature of the mine waste and rehabilitation materials; and the surrounding landscape.

This paper details the process that has been refined and implemented at Roy Hill, to facilitate compliance to design during waste landform construction and progressive rehabilitation, to ensure that high quality rehabilitation outcomes are achieved.
\end{abstract}

Keywords: rehabilitation earthworks, landform design, landform construction, compliance to design

\section{Introduction}

Roy Hill Iron Ore Pty Ltd (Roy Hill) operates the Roy Hill iron ore mine (the Mine) located approximately $110 \mathrm{~km}$ north of Newman and $280 \mathrm{~km}$ south of Port Hedland, in the Pilbara region of Western Australia (Figure 1). The Mine sits within the Roy Hill Pastoral Station and is located to the northeast of the Fortescue Marsh. The Mine is bounded by the Chichester Range to the north and the Hamersley Range to the south.

The overall Roy Hill Operation (the Operation) is a 55 million tonne per annum (Mtpa) iron ore mining, rail and port operation which consists of:

- Conventional open pit, bulk mining operation from multiple production benches.

- 55 Mtpa wet processing plant.

- $344 \mathrm{~km}$ single line, heavy haul railway.

- Purpose built, dedicated two berth iron ore port facility at Port Hedland, capable of receiving, stockpiling, screening and exporting $55 \mathrm{Mtpa}$ (wet) of direct shipped iron ore as lump and fines.

- A Remote Operations Centre is also located alongside the Corporate Headquarters in Perth.

The Mine is a world-class, low phosphorus, Marra Mamba iron ore deposit with a defined mineralisation of more than $2.2 \mathrm{bt}$ of $+50 \%$ Fe iron ore of which $1.2 \mathrm{bt}$ is $+55 \% \mathrm{Fe}$, enough to sustain an original life-of-mine (LOM) of more than 17 years. Roy Hill commenced mining in 2014 and the entire LOM duration will see up to 24 shallow pits (5,518 ha, <110 m depth) across seven mining regions being developed (Figure 2). The current approved disturbance footprint for the Mine (and associated miscellaneous licenses) is 11,993 ha. 


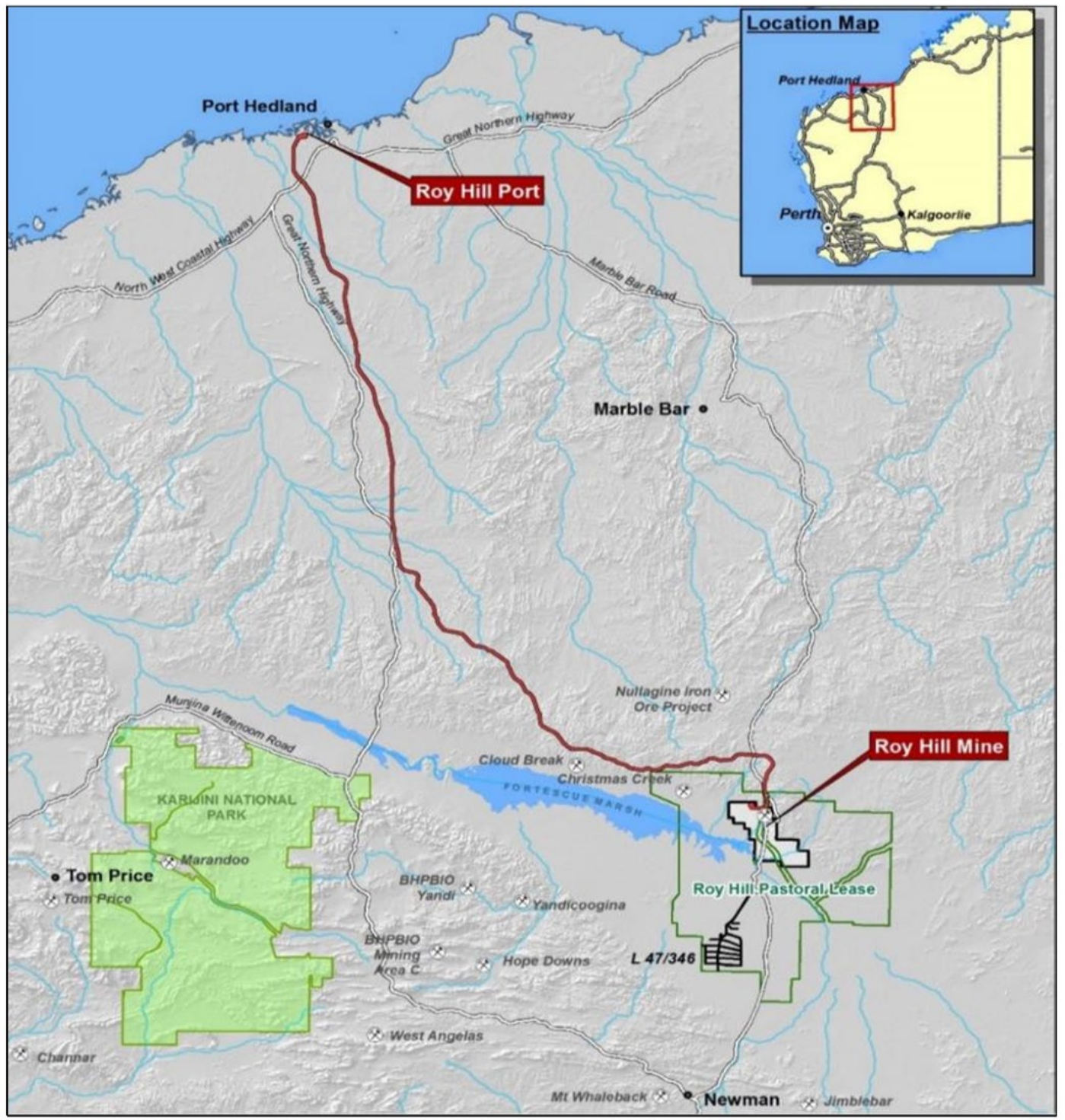

Figure 1 Location of the Roy Hill Mine, rail and port facilities

Mining of bedded Marra Mamba and detrital iron ore is being undertaken in multiple, relatively shallow open pits using conventional open pit mining methods. The mining of each consecutive stage will follow an overall northwest to southeast progression. The progressive mining will allow for the blending of ore to meet customer grade specifications and enable rehabilitation activities to commence early in the mine life. Traditional drill and blast, load and haul mining techniques are utilised, with free dig opportunities being taken where possible to reduce the requirement for blasting.

The large-scale of operations and speed of waste rock landform (WRL) construction at the Mine means that a defined, robust process for WRL design, construction, rehabilitation and compliance audit is essential for efficient and successful implementation of closure works. The relatively early stage of the Mine's operation and commencement of progressive rehabilitation presents an ideal position to improve the current process to achieve optimal rehabilitation outcomes. This is not only important from a regulatory compliance and closure sign-off perspective but also financially, where significant costs can be saved in the long-term if rework of rehabilitated WRLs can be avoided. 


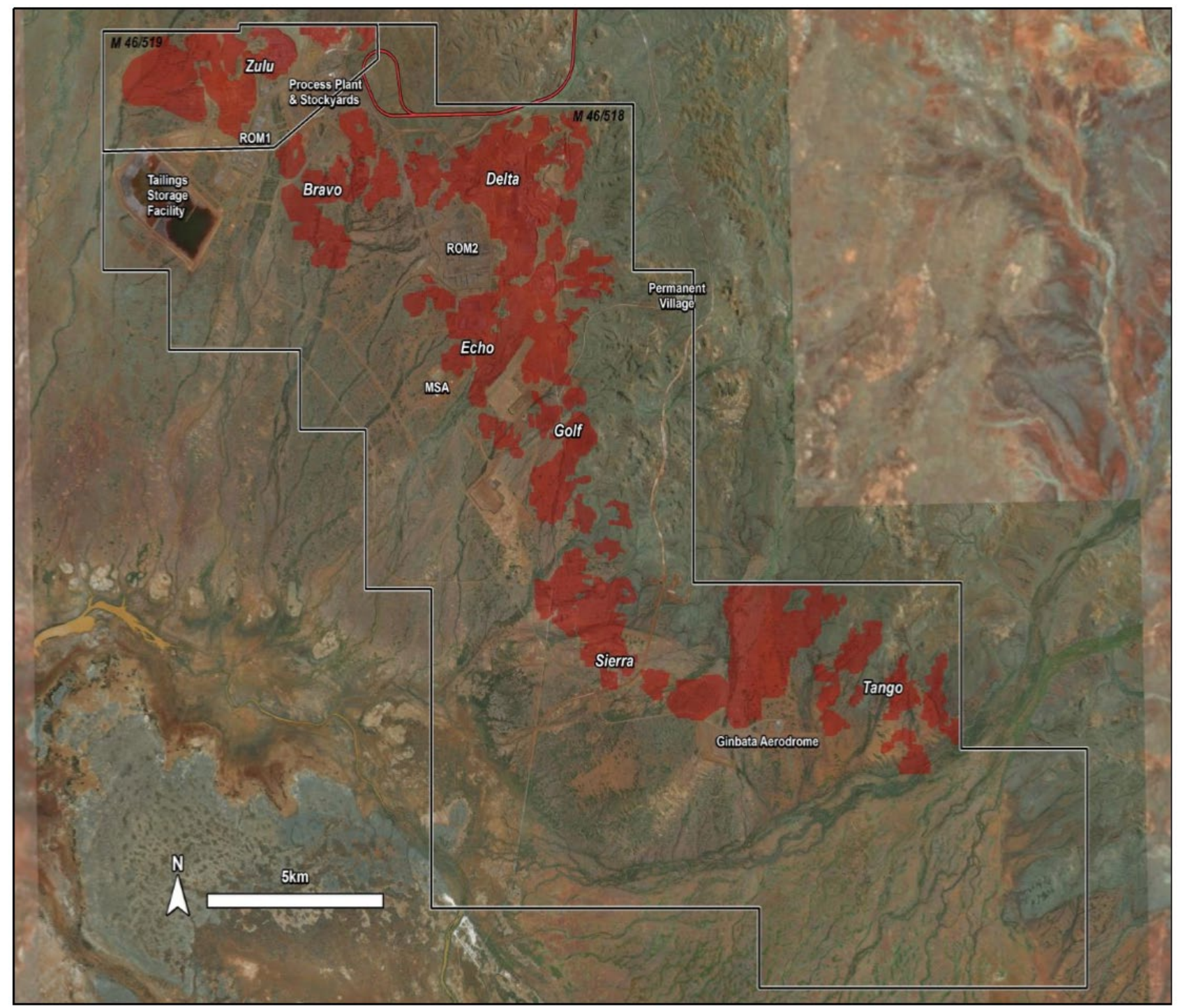

Figure 2 Deposit footprints at Roy Hill

Design, construction and rehabilitation works were completed for a 1.6 ha section of one WRL (WD_M5) in February 2018 (delineated by red polygon in Figure 3(a)). An audit of the rehabilitated area identified several non-conformances with design parameters. A review of the design and construction process was subsequently initiated to identify potential areas for improvement, to improve conformance of construction and rehabilitation works.

\section{$2 \quad$ Existing process review}

A review of the existing WRL design, construction and compliance monitoring process was undertaken in 2018. The tasks undertaken to evaluate the existing process included:

- Review of existing information detailing the existing Roy Hill design and construction process, WRL basis of design (BoD) parameters, soil and mine waste characteristics, mine closure plans, rehabilitation permits, WRL design and audit documentation. 

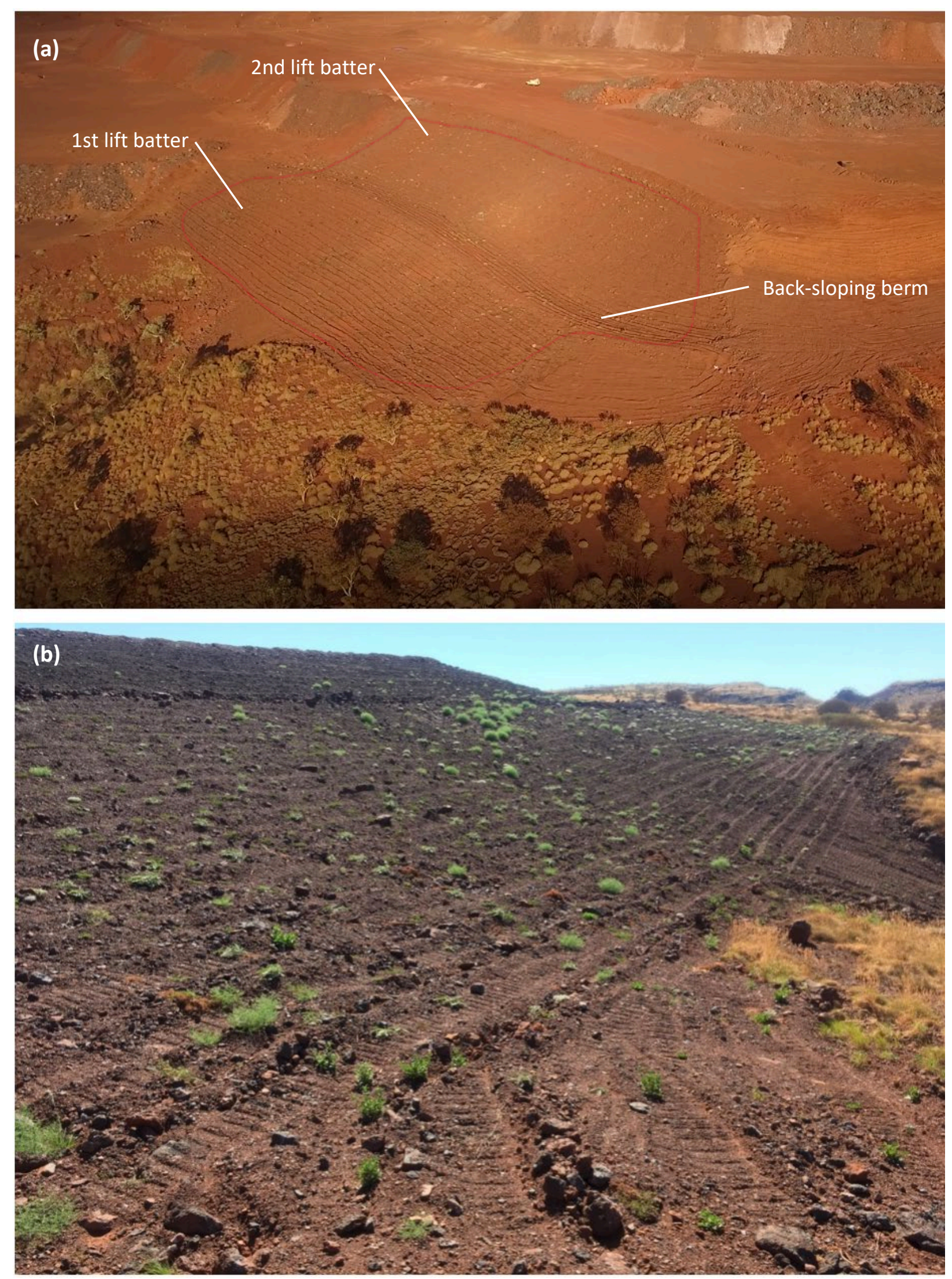

Figure 3 WD_M5 rehabilitation area: (a) aerial of rehabilitation area (red polygon) comprising 1st and 2nd lift batters and back-sloping berm; (b) close-up of ripped and seeded surface of 1st lift batter 
- Site visit and inspection, including:

- Inspection of recently constructed and rehabilitated area of the WD_M5 WRL, rehabilitated December 2017 to February 2018 (Figure 3).

- Review of survey and earthworks machinery guidance capabilities (WENCO GPS machinery guidance system).

- Review of existing methods and equipment utilised for final WRL shaping, ripping and topsoil/rock armour application.

- Interviews with relevant Roy Hill stakeholders, including personnel from the following groups:

- Mine Planning.

- Mine Engineering and Geology.

- Earthworks Supervisors and Operators.

○ Survey.

○ Environmental.

- Identification of alternative methods for the final shaping of the as-dumped WRL, application of topsoil/rock armour, and ripping techniques/equipment.

The interviews with Roy Hill stakeholders was seen as a key component of the review process, providing input from personnel with different areas of expertise and promoting 'buy-in' of the various groups involved in the process.

Based on the review, it was apparent that all the elements of an effective process for the design, construction and closure of the WRLs were present. Some components of the process however, required additional communication to relevant stakeholders, further clarification, or improved rigour. Also identified was the need to implement and formalise 'hold points' at critical stages as part of the process and improve utilisation of the technological survey and machinery guidance tools already available.

The following key gaps and/or potential areas for improvement were identified for the existing WRL design and construction process:

- Lack of a clear, documented process. Some stakeholders unsure of the key elements or components of the process, roles and responsibilities.

- Substantial changes required to the final WRL design (as completed prior to mining) due to noncompliance of the as-dumped and final shaped WRL.

- More rigour was required around checking conformance to design (survey) at each stage of earthworks throughout the process.

- Lack of documented 'hold points' at critical phases in the process (e.g. surface rehabilitation prescriptions being implemented prior to survey and verification of reprofiled batters to confirm compliance to design parameters).

- Earthworks machinery was fitted with WENCO machinery guidance system, but the system was not utilised to its full capacity. Contour ripping was implemented 'by eye' and substantially off contour within the completed WD_M5 rehabilitation area (Figure 4). The WENCO system, which has a centimetre-level accuracy, has capacity to greatly improve compliance to design outcomes if machinery operators are competent with its use.

- Poorly defined and/or uncertainty around tolerance levels for earthworks. A construction tolerance of $\pm 500 \mathrm{~mm}$ had generally been adopted. This large potential deviation from design has implications for final batter shape, slope angles and surface drainage (as seen within the existing 
WD_M5 rehabilitation area). Construction tolerances of 100 to $200 \mathrm{~mm}$ can be readily achieved utilising modern survey and machinery guidance tools.

- Difficulties in WRL reshaping and application of surface rehabilitation prescriptions around a narrow $10 \mathrm{~m}$ wide berm with a steep $\left(11^{\circ}\right)$ back-slope, resulting in a non-conforming berm geometry (Figure 5). Narrow berm allows very little margin for error during construction and rehabilitation earthworks and reduces access to the WRL during earthworks.

- Lack of defined process for non-compliance of closure earthworks, i.e. no process for rectification and rework where the survey conformance audit identifies deficiencies.
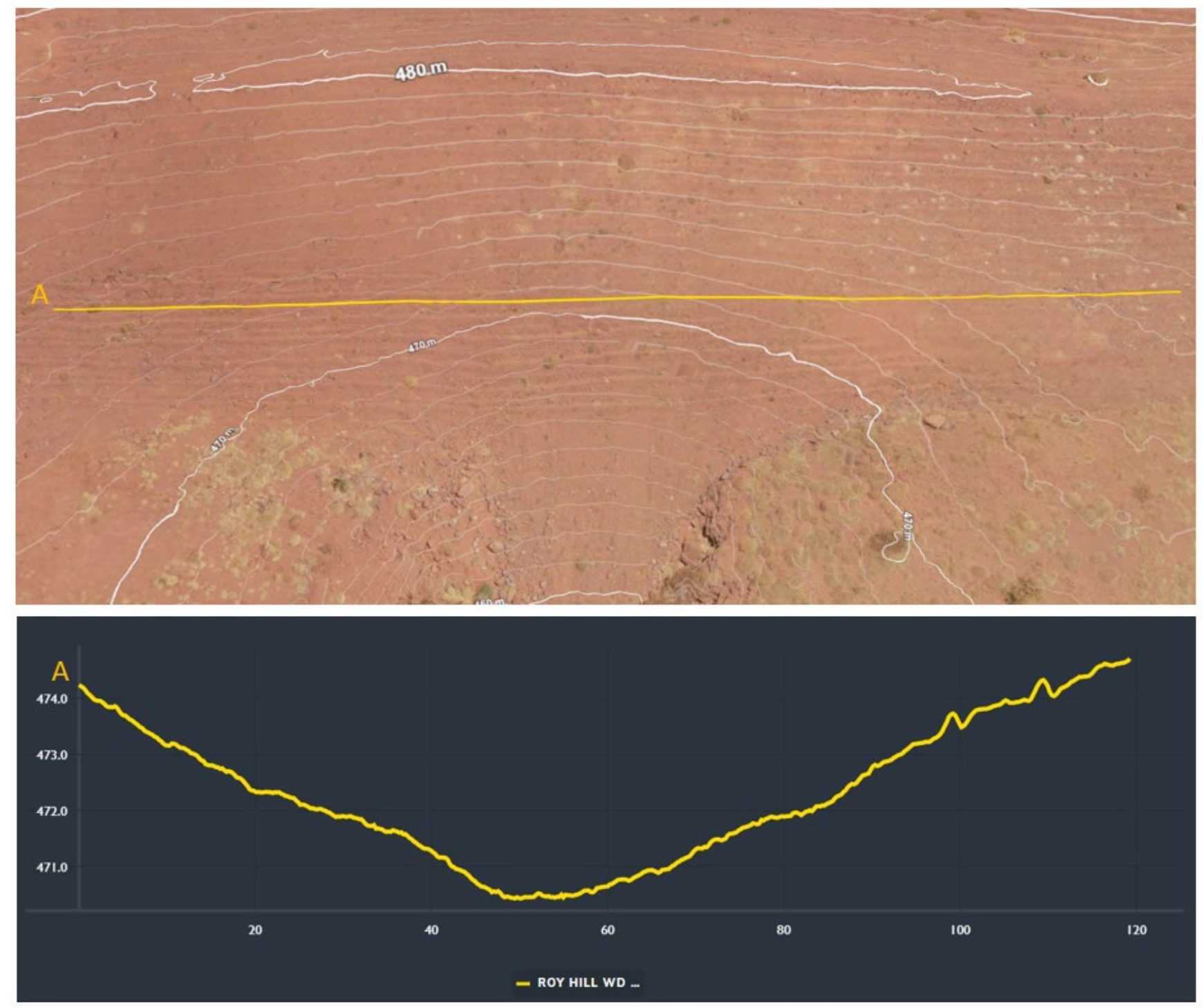

Figure 4 Lower batter and surface contours of WD_M5 rehabilitation area (top), and elevation along rip line ' $A$ ' (bottom) indicating ripping off contour (accurate contour ripping will result in rip lines at a relatively constant elevation) 

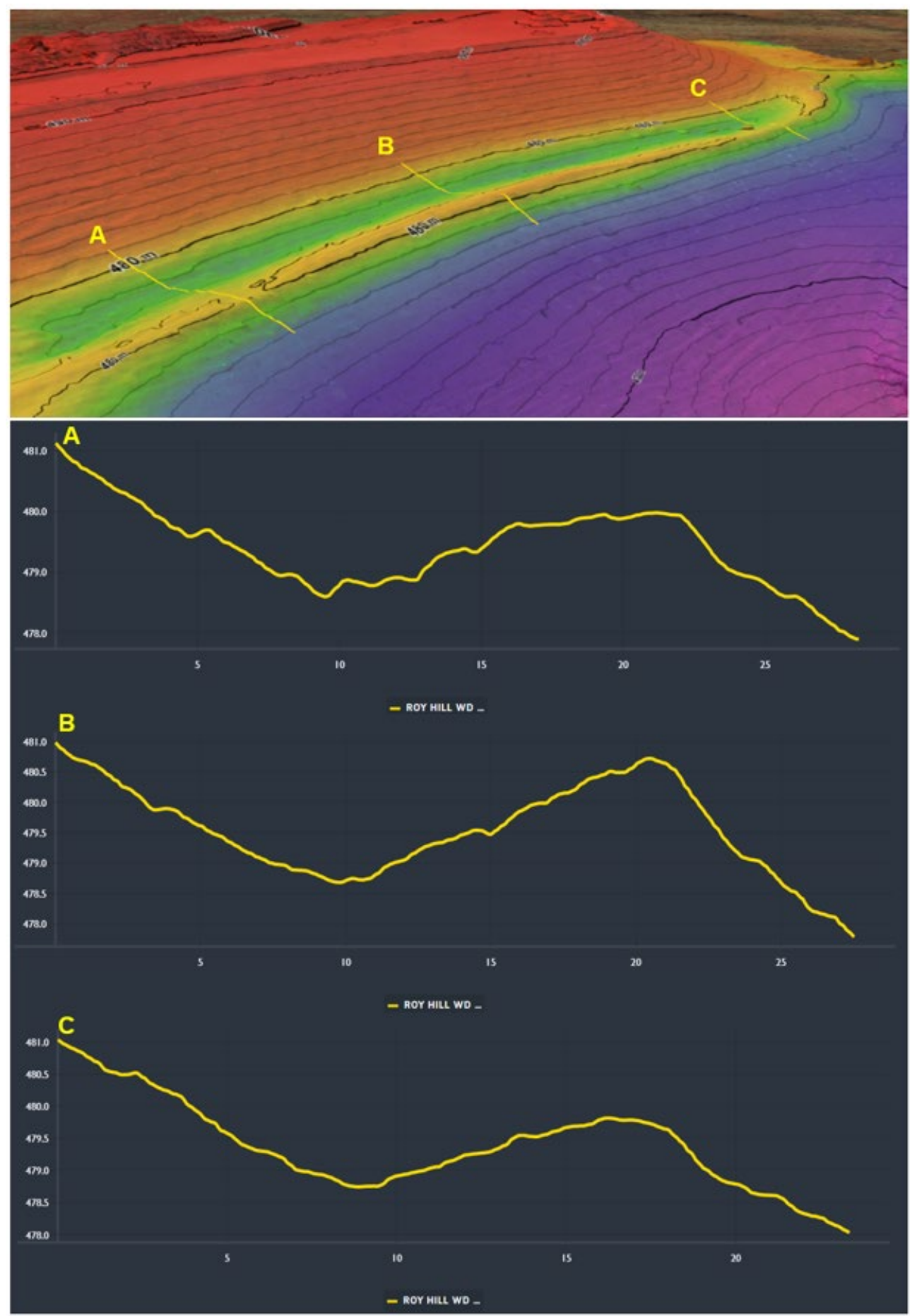

Figure 5 WD_M5 berm elevation (top) and three cross-sections (A, B and C) indicating variable berm geometry and non-conformance with design

\section{Optimising the process}

An optimised WRL design, construction and closure process flow was developed to assist identification of gaps in the existing Roy Hill process. The optimised process is presented in Figure 6 and is described in Sections 3.1 to 3.4. The process is designed to provide regular survey checks and sign-off points to ensure that each stage is compliant with design, before the next phase is implemented. The key improvements made to the Roy Hill process are discussed in Section 4. 


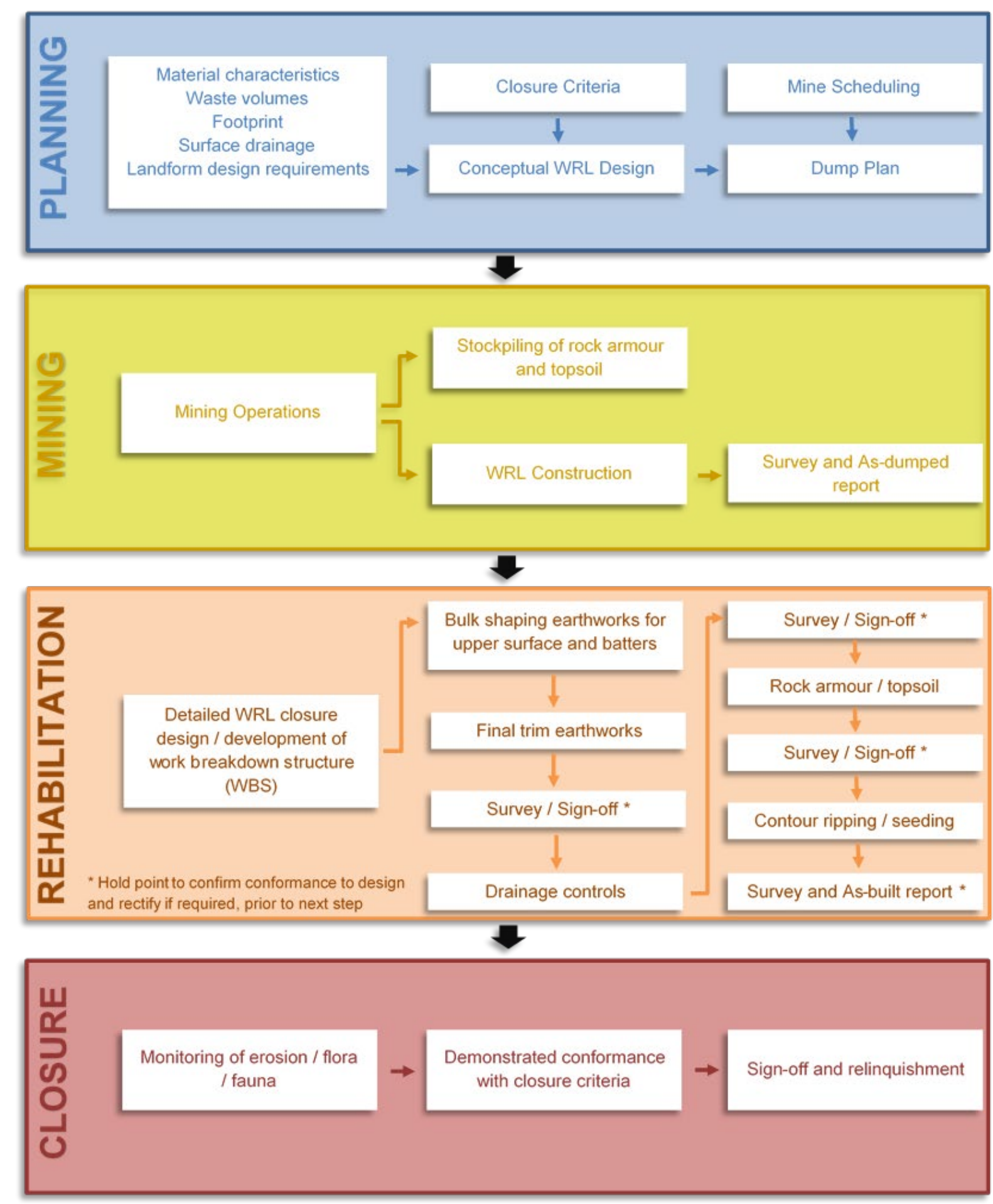

Figure 6 Optimised process flow for waste rock landform design, construction, rehabilitation and closure

\subsection{The Planning Phase}

A conceptual closure design for the WRL is developed, taking into consideration:

- Volumes and characteristics of the mine waste materials from which the WRL is to be constructed.

- WRL footprint constraints including pit boundaries, surrounding topography, surface drainage features and heritage areas. 
- Surface drainage constraints (drainage on and off the WRL).

- Landform design requirements (slope, berm and upper surface geometry), strategic placement of potentially problematic materials, e.g. potentially acid forming (PAF) or highly erodible waste material.

- Surface rehabilitation prescriptions (topsoil and rock armour, ripping, seed and fertiliser application).

- WRL closure criteria considerations (erosion, vegetation, habitat).

In addition to the conceptual WRL closure design, a key output for the 'Planning Phase' is the Dump Plan which details the placement/boundaries of tipping for the mining operation. It is important that the Dump Plan is flexible to a degree (and updated where necessary), to accommodate the inevitable changes in volumes and materials that occur during the mining process.

\subsection{The Mining Phase}

WRL construction is conducted during mining in accordance with the Dump Plan. The 'Mining Phase' also incorporates:

- Identification and strategic placement of potentially problematic waste types (e.g. PAF waste, or highly erodible materials).

- Identification and stockpiling of competent waste rock for use as surface armour (where required).

Following the cessation of load and haul operations to the WRL, the as-dumped WRL should be surveyed to provide the final surface upon which the detailed WRL rehabilitation/closure design is based. This step is critical to identify any variances from the Dump Plan (e.g. footprint changes, waste volume changes, areas of over or under tipping), which need to be incorporated into the detailed rehabilitation/closure design, or rectified prior to the commencement of reshaping works.

\subsection{The Rehabilitation Phase}

The 'Rehabilitation Phase' commences with the detailed rehabilitation/closure design of the WRL, whereby the landform design parameters (as identified in the 'Planning Phase') are applied to the as-dumped WRL surface.

The earthworks required to shape the WRL in accordance with the detailed rehabilitation/closure design are divided into manageable sections, and work packs for the individual WRL sections which are developed. These documents detail the work breakdown structure (WBS) including hold/sign-off points, design specifications and tolerances, bill of quantities, and roles and responsibilities for the rehabilitation earthworks.

The design surface for the relevant section of the WRL is prepared and uploaded to the WENCO GPS guidance systems in earthworks machinery.

Ongoing survey throughout the closure works is critical to facilitate compliance with the closure design. Surveys should be completed at regular periods throughout the closure works and at all hold points to assess and enable rectification of non-conformances. This is particularly important once the final shaping earthworks are completed, prior to the application of surface rehabilitation prescriptions, to identify material deviations from the design surface.

Additionally, at this stage of the process, geological assessment of the waste materials present at the surface of the shaped WRL should be incorporated into the survey to inform the final rock armouring requirements.

Once the shaped WRL is signed off by the Environmental Department, Work Instructions are issued for implementation of surface rehabilitation prescriptions (rock armour/topsoil), and relevant information is 
loaded into machinery GPS guidance systems. Again, survey and sign-off is recommended between each stage to verify compliance with nominated construction tolerances. Following contour ripping and seeding of the rehabilitated surface, a final survey is conducted and an 'As-built report' (detailing the final dimensions and geometry) for the WRL is generated and the WRL is signed off as being completed. The As-built report and associated construction documentation can form the basis of compliance with landform components of the mine closure planning closure criteria.

\subsection{The Closure Phase}

The 'Closure Phase' of the process essentially comprises monitoring of rehabilitation and closure parameters (erosion, vegetation growth, weed growth etc.) to demonstrate conformance with WRL closure criteria over a defined time frame.

\section{$4 \quad$ Implementation of process improvements}

All the elements for an effective process were already in place at Roy Hill. A summary of the key components identified to improve the existing process and overall outcomes were as follows:

- Greater attention required at the conceptual WRL design stage to surrounding topography and associated implications for the final shape of the WRL (e.g. constructability, drainage and longterm erosion etc.).

- Considered review of the WRL design parameters, particularly around berm widths on WRLs. Wider berms (e.g. $20 \mathrm{~m}$ wide with $5^{\circ}$ back-slope) give greater flexibility to account for variable materials and hydraulic properties, provide a greater capacity to cope with runoff from extreme rainfall events, provide a margin for error during construction and less issues with constructability.

- Detailed WRL design and associated Work Instructions for WRL shaping earthworks should be based on the final as-dumped WRL surface (accounting for any changes that have occurred during mining operations).

- Define appropriate, realistic construction tolerances for all earthworks and convey to Roy Hill stakeholders as to why these are important. Experience from similar mining operations indicate that substantially lower tolerances (i.e. greater accuracy), than those currently issued by Roy Hill, can be achieved. It was recommended that an initial tolerance of $200 \mathrm{~mm}$ for WRL shaping and $100 \mathrm{~mm}$ for surface rehabilitation prescriptions is implemented.

- Improve utilisation of the WENCO GPS guidance system. Information from Survey personnel suggested that the WENCO system has a far greater capacity for machinery guidance and monitoring than what was being utilised, for example:

- Previously, only the crest and toe lines for each batter were loaded into the WENCO system, however it is possible for the design surface to be uploaded, which provides a greater level of information and guidance for the earthworks operators.

- Can be used to guide contour ripping works (previously implemented 'by eye').

- Conduct WENCO training for earthworks/rehabilitation machinery operators and supervisors.

- Train earthworks machinery operators and supervisors on desired outcomes, importance of earthworks accuracy and implications of non-compliance with design.

- Formalise hold points/sign-off stages for survey control and conformance assessment after key tasks have been completed (as detailed within Figure 6).

- Document and formalise the process for non-compliance with design so that non-compliance can be rectified. 


\section{$5 \quad$ Improved construction and rehabilitation outcomes}

Implementation of the refined process components has streamlined rehabilitation works, increased awareness of rehabilitation requirements across numerous departments, and improved conformance to design parameters.

Improved utilisation of the WENCO machinery guidance system and formalisation of hold points for survey/audit of conformance to the design, has immediately improved the outcomes of surface rehabilitation earthworks (e.g. rock armour/topsoil application depth and contour ripping), therefore reducing the potential requirement for future rework of the rehabilitated areas.

In the long-term, the reduced requirement for potential rework and repairs, the capacity to better track closure works and improve the closure design, is expected to result in a considerable reduction of closure costs.

\section{Acknowledgement}

The authors thank Roy Hill personnel, Mine Earth and Gerrard Consulting. 
